\title{
Control of Drum Boiler Dynamics via an Optimized Fuzzy Controller
}

\author{
D. Pelusi, R. Mascella, L. Tallini \\ Faculty of Communication Sciences \\ University of Teramo \\ Teramo, Italy \\ \{dpelusi, rmascella, 1tallini\}@unite.it
}

\author{
L. Vazquez, D. Diaz \\ Faculty of Electrical Engineering \\ University of Oriente \\ Santiago of Cuba, Cuba \\ \{lvazquez,ddiaz\}@uo.edu.cu
}

\begin{abstract}
Drum Boilers are an important component of many modern industrial facilities. Generally, the simulation of tailormade Drum Boilers starts up at each steady-state condition inside each operation region. The problem of such systems is the control of parameters, as level and pressure, around a reference value. The design of control algorithms can be accomplished using intelligent techniques such as Fuzzy Logic and Genetic Algorithms. This paper proposes a Fuzzy Controller, optimized by Genetic Algorithms, able to control Drum Boiler dynamics. Genetic procedures are used to obtain optimal Membership Functions and Fuzzy rules. The results show that the timing performance of the control system are improved reducing the settling time and the rise time. Moreover, the system shows good robustness to different reference values.
\end{abstract}

Keywords-component: Drum Boiler, Fuzzy Controller, Genetic Algorithms, Optimization Techniques

\section{INTRODUCTION}

Pressure and water level are critical parameters in Drum Boilers control. In order to avoid water carryover, the Drum level must lie within the limits specified by the boiler manufacturer. A too low water level could cause Boiler damages. On the other hand, the pressure determines the steam flow rate value which is required to feed the turbine to produce output power. If the steam temperature is greater than the permitted one, a metal overheat can occur with contingently microscopic metal fractures. Naghizadeh et al. [1] proposed a simple procedure to extract the model parameters of a real steam power plant Drum Boiler based on heat balance map and thermodynamic tables for power system dynamic stability studies. A careful attempt has been made to derive the complete mathematical model of a Drum Boiler in the state space domain [2].

This paper takes into account a Drum Boiler simulator using the nonlinear P16-G16 Drum Boiler model, the dynamics of which are presented in [3] and its valve actuators in [4]. These researches were based on the Boilerturbine plant P16/G16, which is oil-fired and the rated power is $160 \mathrm{MW}$, at the Sydvenska Kraft AB Plant in Malmo, Sweden. The challenge of this work is to counteract the effects of Drum Boiler disturbance inputs with a suitable Fuzzy Logic Controller. The idea is to design a Fuzzy Controller (FC), powered by Genetic Algorithms, able to keep the level close to a reference level taking into account disturbances.

\section{LITERATURE SURVEY}

Many efforts have been made to monitor the Boiler temperature and pressure by means of Programmable Logic Controllers (PLC) [5]. Zhuo et al. [6] designed a control scheme of feed-forward Proportional Integral Derivative
(PID) control for Drum water level. However, PID controllers are not adequate when there are fluctuations and changing environment in the system to be controlled. These situations require a different approach to solve the control problem. Intelligent techniques such as Fuzzy Logic can be applied to improve the control performances. Dey et al. [7] designed a water level controller using Fuzzy Logic. The water level control of Boilers can be monitored by suitable Fuzzy controllers [8]. The Fuzzy controllers can solve the problem of external disturbances in Circulating Fluidized Bed (CFB) Boilers [9]. Fluctuant temperatures conditions are unfavorable for power generation: an optimal Fuzzy controller is proposed to solve such problem [10]. The feature of this approach is the Fuzzy rules reduction from 27 to 3, with an improvement of the rules evaluation time. Corrosion Boiler parts can be avoided using Fuzzy Logic to control the temperature and pressure entrance into the Boiler itself [11].

Intelligent techniques such as Genetic Algorithms (GA) are used to control the Boiler parameters. Relevant results have been achieved by Dimeo et al. [12] for the control of a Boiler-turbine plant. Thanks to the application of GA to the control system, good steady-state tracking results have been achieved. The problem of designing a controller for a highly coupled constrained nonlinear Boiler turbine system is addressed by $\mathrm{Wu}$ et al. [13]. In this work, a GA has been implemented as an online discrete time tool to solve the nonlinear model predictive control problem. Hassanein et .al. [14] proposed a good solution to control both the water/steam temperature and the water level control loops of a Boiler. In this work, Fuzzy Logic and GAs were applied to optimize the width and the scaling factors of Membership Functions.

Fuzzy Logic and Genetic Algorithms approaches have been applied to various research fields. One of the main 


\section{PELUSI et al: CONTROL OF DRUM BOILER DYNAMICS VIA AN OPTIMIZED FUZZY CONTROLLER}

problems in electrical distribution systems is the reactive power flow. This problem causes active power transmission reduction, power losses decreasing, and the drop voltage increase. A good solution is proposed by Nasri et al. [15] by employing two algorithms: a Fuzzy Logic Controller algorithm for critical nodal detection and Genetic Algorithm Optimization for optimal capacitor seizing. Advanced $\mathrm{pH}$ control schemes have been designed through intelligent controllers for the $\mathrm{pH}$ neutralization process [16]. Suitable combinations of intelligent techniques have been proposed by Pelusi for different applications. [17], [18], [19], [20], [21], [22], [23], [24], [25].

Among several research projects oriented to determine the power plant dynamics, the following ones can be considered: a $600 \mathrm{MW}-\mathrm{US}$ power plant based on a forced circulation Drum Boiler [26], and a 160 MW-Sweden P16G16 power plant with a natural circulation Drum Boiler [27]. In addition, low-order models for model based control design are also available, see e.g. [3], [28], [29] and [30].

\section{DESIGN AND OPTIMIZATION OF THE FUZZY CONTROLLER}

Inspired by the computational thinking (see [31]), this paper uses on a tailor made simulator of very important industrial processes which are sourced with heat flows (see Figure 1).

For the special requirements of the steam power industry, International Association for the Properties of Water and Steam (IAPWS) also maintains a separate formulation for industrial use. This paper inserts and uses the XSteam file for Matlab, which is an implementation of the IAPWS IF97 standard formulation [32]. It provides accurate data for water and steam and mixtures of water and steam properties from 0:1000 bar and from 0:2000 deg C.

The model includes not only the Drum Boiler model but also valve actuators dynamics, and linear dynamics for sensor transmitters are inserted. The Drum Boiler control requires two valves: one to control the feedwater mass flow entering the Drum and another to control the fuel oil mass flow to burners. The steam mass flow rate measuring is necessary to perform a feedforward control. Instead of feedback and feedforward strategies, Pelusi and Vazquez [17] proposed intelligent algorithms to control Drum Boiler dynamics [33]. Following this research line, further investigations lead to the design of a Fuzzy Controller optimized through GAs.

The first choice to design a Fuzzy Controller is the Membership Functions shape. As in [17], we consider triangular/trapezoidal shapes, but good results have been also achieved using Gaussian MFs in signal processing applications [25]. Moreover, to define the number of MFs for each Fuzzy input/output, we take into account the findings of Chopra et al. [34]. The aim is to design a Fuzzy Controller with a smaller number of rules leading to a shorter computational time. Therefore, to find a good compromise between the complexity and the control goodness of the FC, seven MFs for each input/output are chosen. The Membership Functions are: Negative-Big (NB), Negative-
Medium (NM), Negative-Small (NS), Zero-Error (ZE), Positive-Small (PS), Positive-Medium (PM) and PositiveBig (PB).

In order to control the level $y$ of the Drum Boiler, we consider the Fuzzy inputs error $\mathrm{e}$ and change in error de, defined as

$$
\begin{aligned}
& e(i)=y\left(t \_1\right)-1 \_r \\
& \operatorname{de}(i)=e(i)-e(i-1)
\end{aligned}
$$

where $t$. 1 lies in $[0, t]$ and $i=1,2, \ldots, n$, with $n$ number of comparisons between $\mathrm{y}\left(\mathrm{t} \_1\right)$ and the reference level $1 \_\mathrm{r}$. Moreover, we refer to o(i) as the output of the $\overline{\mathrm{F} C}$. According to [34] and [17], the Fuzzy rules of Table I are defined. The rules of this table are of the form, "If $e$ is NB And de is NB, then out is NB".

In order to reduce the difference between the level of the Drum Boiler and the reference level, fuzzy inputs with membership functions number greater than 3 are chosen. In this way, the precision of the fuzzy system is increased. In fact, the parameters of the Drum Boiler such as pressure and level need high precision. The optimal precision is achieved by using seven MFs.

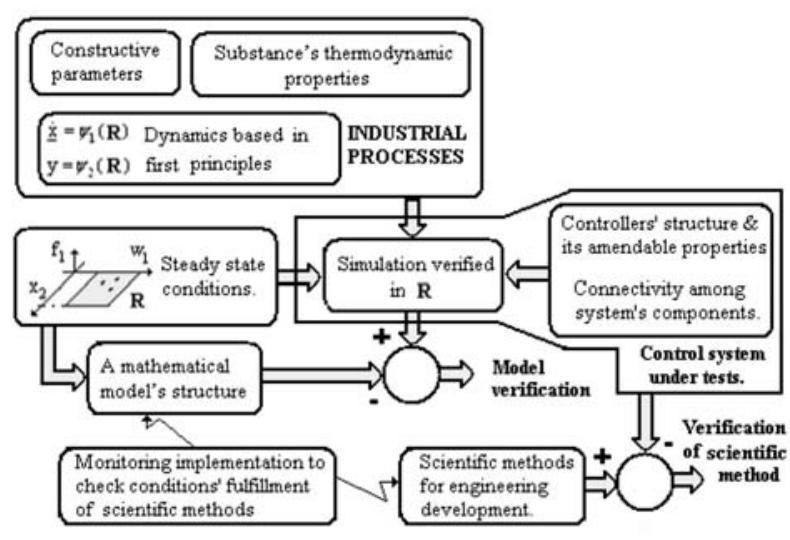

Figure 1. A computation structure for tailor made Drum Boiler simulator development.

TABLE I. FUZZY RULES OF THE FUZZY CONTROLLER

\begin{tabular}{|c|c|c|c|c|c|c|c|}
\hline $\boldsymbol{e} / \boldsymbol{d} \boldsymbol{N}$ & $\boldsymbol{N B}$ & $\boldsymbol{N M}$ & $\boldsymbol{N S}$ & $\boldsymbol{Z E}$ & $\boldsymbol{P S}$ & $\boldsymbol{P M}$ & $\boldsymbol{P B}$ \\
\hline $\boldsymbol{N B}$ & NB & NB & NB & NM & NS & NS & ZE \\
\hline $\boldsymbol{N M}$ & NB & NM & NM & NM & NS & ZE & PS \\
\hline $\boldsymbol{N S}$ & NB & NM & NS & NS & ZE & PS & PM \\
\hline $\boldsymbol{Z} \boldsymbol{E}$ & NB & NM & NS & ZE & PS & PM & PB \\
\hline $\boldsymbol{P S}$ & NM & NS & ZE & PS & PS & PM & PB \\
\hline $\boldsymbol{P M}$ & NS & ZE & PS & PM & PM & PM & PB \\
\hline $\boldsymbol{P B}$ & ZE & PS & PS & PM & PB & PB & PB \\
\hline
\end{tabular}

Having defined the Fuzzy Controller architecture, it is very important to optimize the MFs and the rules. In the literature, there are techniques which employ genetic optimizing procedures [25], [35], [36]. Pelusi [24] proposed evolutionary search procedures to find the best Fuzzy rules to improve the control of industrial processes. Therefore, we 


\section{PELUSI et al: CONTROL OF DRUM BOILER DYNAMICS VIA AN OPTIMIZED FUZZY CONTROLLER}

apply Genetic Algorithms to Fuzzy Controller to improve the performances of the control system.

The genetic algorithms are search methods based on the darwinian theory of fittest survival. They search a solution space for an optimal solution to a problem [37]. In our case, the best MFs and the more relevant rules of the FC must be researched. In order to do this, a suitable fitness function has to be defined. The choice of the fitness function is problem dependent [38], [39], [40]. Because our target is to reduce the difference defined in (1), the following fitness function is defined:

$$
f(x)=1 /\left(1+x^{\wedge} 2\right)
$$

where $\mathrm{x}$ is the sum of $\mathrm{i}$ from 1 to $\mathrm{n}$ of e(i). This means that, the genetic procedure searches the best value of $\mathrm{f}$ to make $\mathrm{y}\left(\mathrm{t} \_1\right)$ very close to 1_r .

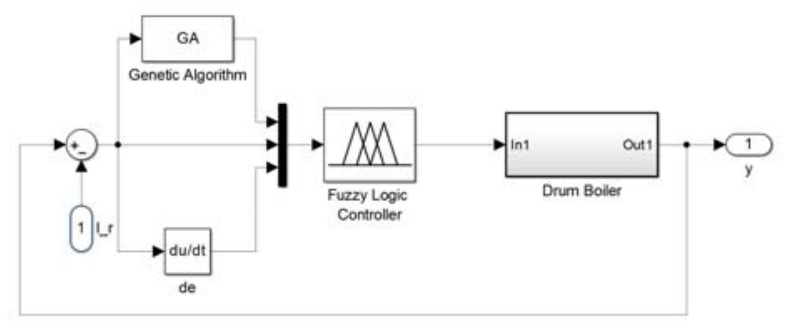

Figure 2. Block diagram of optimization architecture.

Now, we describe the optimization process of the MFs and the rules of the Fuzzy Controller. Figure 2 shows the block diagram of the optimization architecture. The sum node computes the difference between the output level y of the Drum Boiler and the reference level 1_r . In others terms, the error e defined in (1) is computed and sent to the $\mathrm{du} / \mathrm{dt}$ and GA blocks. The du/dt block calculates the change in error de (see (2)) whereas the GA block supplies to the Fuzzy Logic Controller block the MF parameters and the weights of the Fuzzy rules.

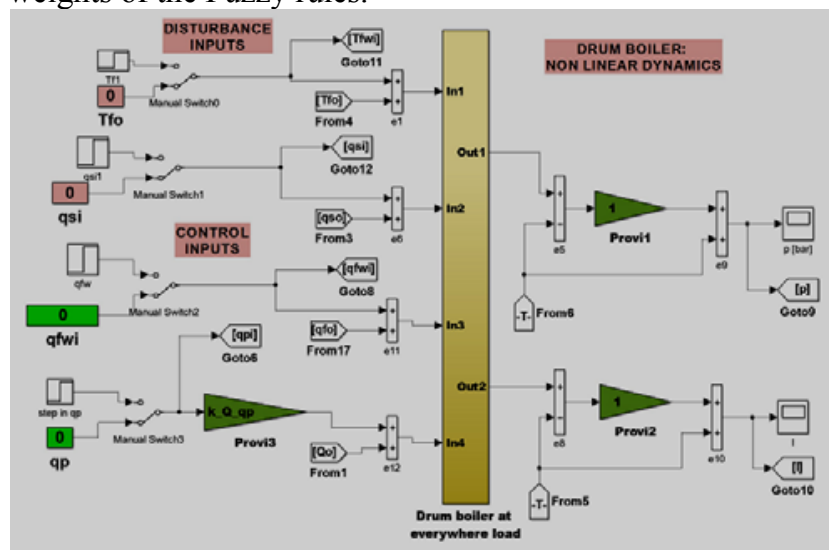

Figure 3. Drum Boiler Simulator.

The Fuzzy Logic Controller, taking into account the outputs of $\mathrm{du} / \mathrm{dt}$ and GA and the input e, tunes the control inputs of the Drum Boiler through its output o . In particular, the Fuzzy Controller changes the parameters step time and final value of qfw input of the Drum Boiler Simulator [33] (see Figure 3 and the Appendix). The Drum Boiler gives a new value of the level $y$ which is newly compared with the reference level value 1_r through feedback. Subsequently, the process restarts.

Once that the optimal value of the fitness function (3) is achieved, the Fuzzy Logic Controller is optimized and ready to work.

\section{DISCUSSION OF THE RESULTS}

In order to simulate the described optimization structure, Matlab-Simulink development environments are used. The Fuzzy Controller is based on the Mamdani Fuzzy inference and the "centroid" is the defuzzification method. The Genetic Algorithm is characterized by a population equal to 100 and a generation equal to 20 . The last parameters have a huge influence on the convergence time of the system to the optimal solution. To avoid computer time problems, the comparison number $\mathrm{n}$ (i.e. the number of times which feedback occurs) is equal to 10 . Moreover, a value of $1.35 \mathrm{~m}$ is established for the reference level $1 \mathrm{r}$.

Figures 4 and 5 show the optimized MFs of the Fuzzy inputs e and de, whereas Figure 6 shows the optimal MFs of the Fuzzy output o . Note that, the MFs shapes of the Fuzzy inputs are very narrow: this means that the control system needs of good precision to work.

In Table II the optimal weights values of the Fuzzy rules defined in Table I are shown. The least relevant rule is "If $\mathrm{e}$ is NM and de is PM then o is ZE", which has a weight of 0.0090 . Observing Table II it follows that rules with error $\mathrm{e}=\mathrm{PM}$, have poor relevance on the optimization of the control architecture.

Having obtained the optimal MFs and the rules, the control system is ready to work for each reference value of level. The goodness of a control system depends on the settling time, the rise time and the overshoot in a step response. In Figure 7 the step response of a system without $\mathrm{FC}$ is shown. Note that, the overshoot is zero, the settling time is $57.7 \mathrm{~s}$ and the rise time is $32.0 \mathrm{~s}$ (see also Table III). Using the optimized FC, the values are reduced to $12.8 \mathrm{~s}$ and $7.1 \mathrm{~s}$ for the settling and the rise time respectively. Therefore, the settling time and the rise time are reduced by $44.5 \%$. Figure 8 shows the step response of the Drum Boiler with Fuzzy Controller. It is obvious that the Fuzzy Controller improves the timing performances of the system (see Table III).

To evaluate the robustness properties of our system, we consider two different reference values: $1 \_r=1.55 \mathrm{~m}$ and $1 \mathrm{r}=1.05 \mathrm{~m}$. Remember that the level reference established for the optimization process is $1 \_r=1.35 \mathrm{~m}$. Figure 9 shows the trend of the Drum Boiler level over time with $1 \_r=1.55 \mathrm{~m}$. The solid line represents the level without the

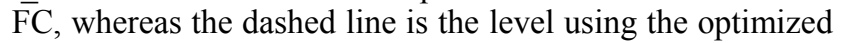
FC. Note that the curves have the same trend up to $t=40 \mathrm{~s}$. Subsequently, the dashed line is under the solid one up to 


\section{PELUSI et al: CONTROL OF DRUM BOILER DYNAMICS VIA AN OPTIMIZED FUZZY CONTROLLER}

$\mathrm{t}=55 \mathrm{~s}$. For time values greater than $55 \mathrm{~s}$ and less than $120 \mathrm{~s}$ , the level tuned by the FC is over the level without FC. From $\mathrm{t}=120 \mathrm{~s}$ forward, the dashed line is under the solid line. The results show that with a reference value of $1.55 \mathrm{~m}$, the qualitative trend of the Drum Boiler level is the same. We test the performance of the FC establishing a reference level less than $1.35 \mathrm{~m}$. Figure 10 shows the trend of the level with $1 \mathrm{r}=1.05 \mathrm{~m}$. The results are opposite to the previous ones because where the dashed line was under the solid one, now it is over and vice versa. Similar results are achieved considering various values of $1 \mathrm{r}$ : this means that a good level of robustness is achieved.

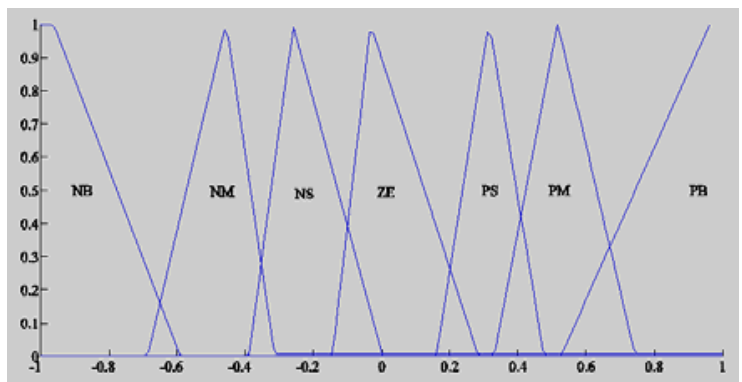

Figure 4. Optimized Membership Functions of the Fuzzy input e

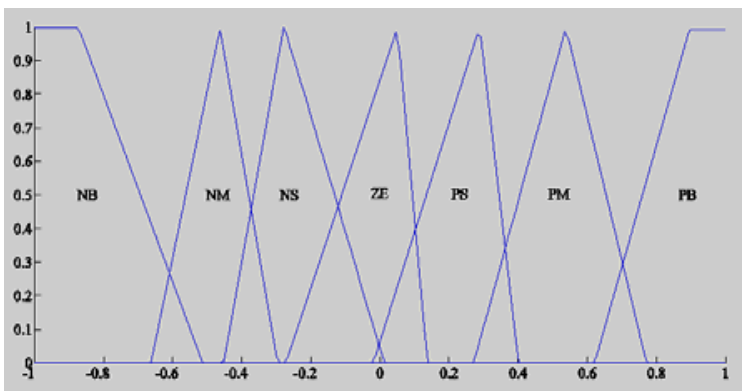

Figure 5. Optimized Membership Functions of the Fuzzy input de

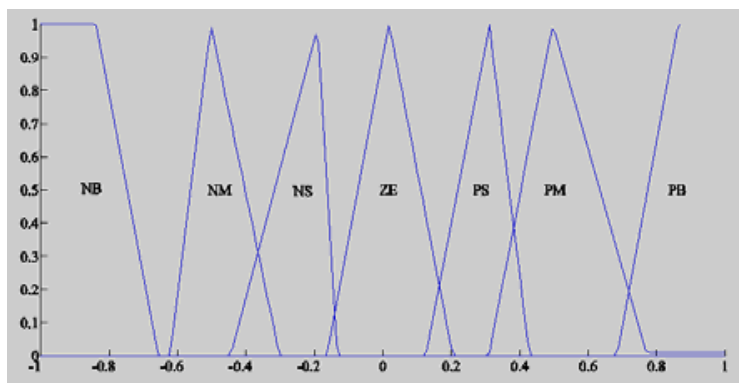

Figure 6. Optimized Membership Functions for the Fuzzy output o

TABLE II. OPTIMAL WEIGHTS OF THE FUZZY RULES

\begin{tabular}{|c|c|c|c|c|c|c|c|}
\hline $\boldsymbol{e} / \boldsymbol{d} \boldsymbol{e}$ & $\boldsymbol{N B}$ & $\boldsymbol{N M}$ & $\boldsymbol{N S}$ & $\boldsymbol{Z E}$ & $\boldsymbol{P S}$ & $\boldsymbol{P M}$ & $\boldsymbol{P B}$ \\
\hline $\boldsymbol{N B}$ & 0.8801 & 0.8632 & 0.6069 & 0.5266 & 0.4741 & 0.6023 & 0.4753 \\
\hline $\boldsymbol{N M}$ & 0.6727 & 0.2124 & 0.3895 & 0.9352 & 0.1297 & 0.0090 & 0.6042 \\
\hline $\boldsymbol{N S}$ & 0.7564 & 0.0808 & 0.8929 & 0.2839 & 0.7562 & 0.0812 & 0.5132 \\
\hline $\boldsymbol{Z E}$ & 0.3986 & 0.7782 & 0.8332 & 0.7008 & 0.7482 & 0.2133 & 0.3924 \\
\hline $\boldsymbol{P S}$ & 0.7188 & 0.3082 & 0.0369 & 0.0407 & 0.5423 & 0.9156 & 0.3683 \\
\hline $\boldsymbol{P M}$ & 0.0631 & 0.4676 & 0.6069 & 0.7469 & 0.1712 & 0.0980 & 0.0781 \\
\hline $\boldsymbol{P B}$ & 0.9471 & 0.0298 & 0.5295 & 0.4699 & 0.3907 & 0.6348 & 0.3208 \\
\hline
\end{tabular}

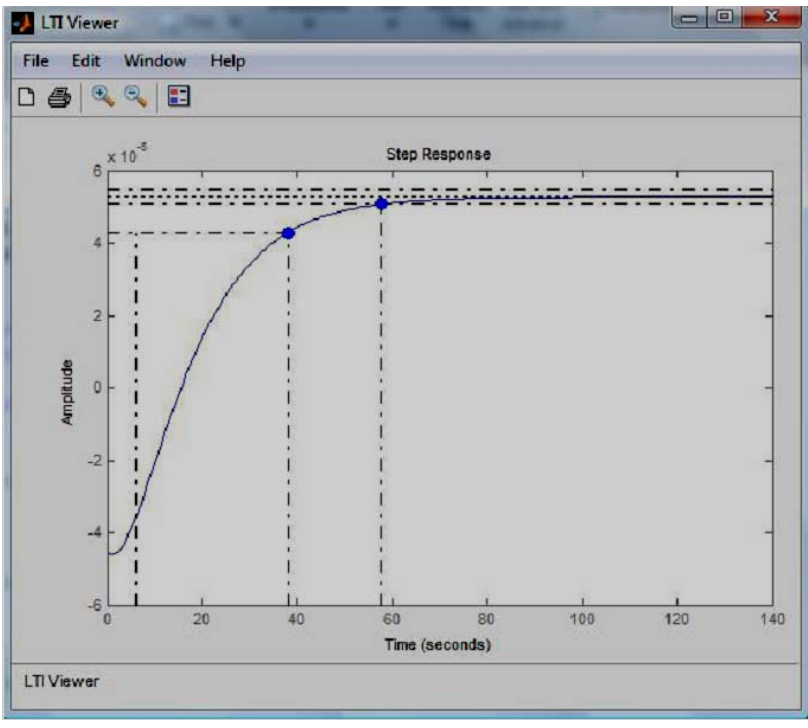

Figure 7. Step response of the Drum Boiler without Fuzzy Controller

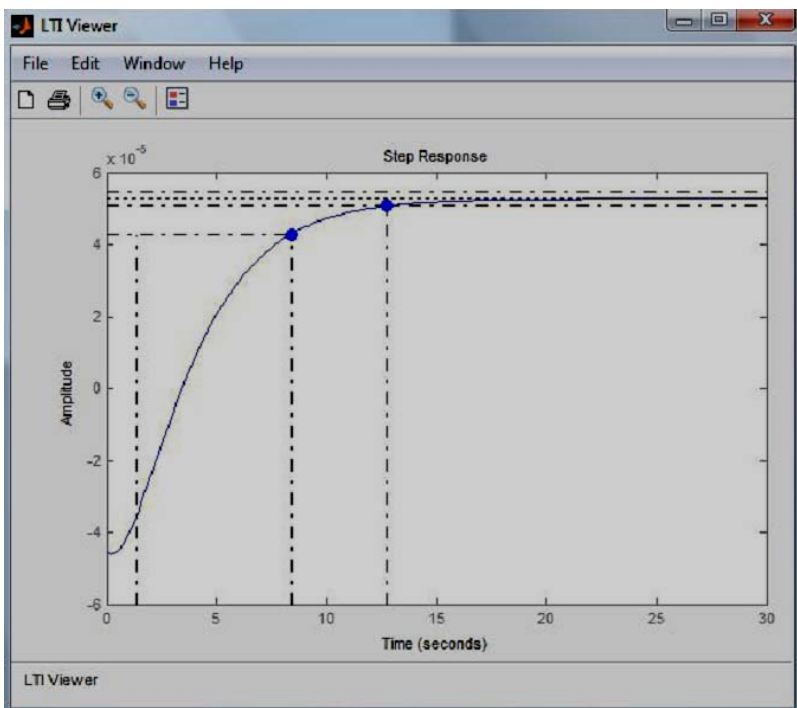

Figure 8. Step response of the Drum Boiler with Fuzzy Controller

TABLE III. COMPARISON OF THE SETTLING AND THE RISE TIME WITHOUT AND WITH FUZZY CONTROLLER

\begin{tabular}{|c|c|c|}
\hline & Drum Boiler without FC & Drum Boiler with FC \\
\hline Settling time & $57.7 \mathrm{~s}$ & $12.8 \mathrm{~s}$ \\
\hline Rise Time & $32.0 \mathrm{~s}$ & $7.1 \mathrm{~s}$ \\
\hline
\end{tabular}




\section{PELUSI et al: CONTROL OF DRUM BOILER DYNAMICS VIA AN OPTIMIZED FUZZY CONTROLLER}

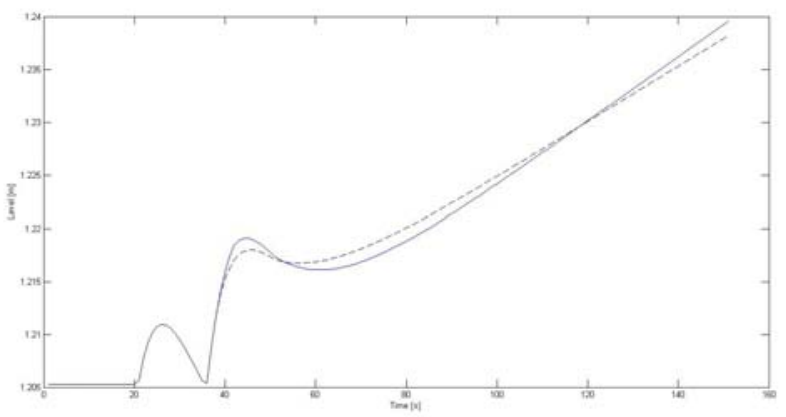

Figure 9. Level of the Drum Boiler with reference value of $1.55 \mathrm{~m}$

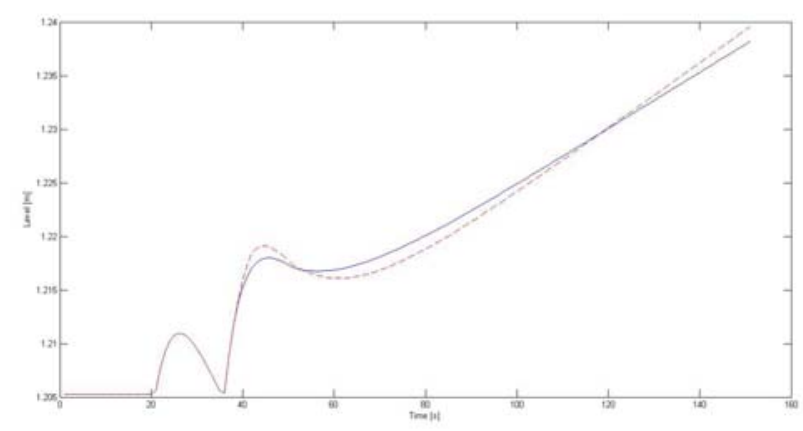

Figure 10. Level of the Drum Boiler with reference value of $1.05 \mathrm{~m}$

\section{CONCLUSIONS AND FUTURE WORK}

Industrial processes need of controllers able to keep a reference value, independently by disturbance inputs. Intelligent techniques are useful to design optimal control systems. As an example, suitable combinations of Fuzzy Logic and Genetic Algorithms give good results. The proposed Fuzzy Controller, powered by Genetic Algorithms, assures a better timing performance with the reduction of the settling time and the rise time of about 44 per cent. Moreover, the optimized architecture shows a good robustness to various reference levels. Further research works will concern the design of controllers based on intelligent techniques such as the Neural Networks.

\section{REFERENCES}

[1] Naghizadeh R. A.,Vahidi B., Tavakoli M. R. B., “Estimating the Parameters of Dynamic Model of Drum Type Boilers Using Heat Balance Data as an Educational Procedure", IEEE Transactions on Power Systems, Vol. 26, No. 2, May 2011

[2] Mrunalini K., Kundu P., Dutta K K., “State Space Model for Drum Boiler", IE (I) Journal, Vol 86. pp 260-267. 2006

[3] Bell R.D., Astrom K.J., “A Low Order Nonlinear Dynamic Model for Drum Boiler - Turbine - Alternator", Unit.LUTFD2 (TFRT7162)/1-039. ITL. Sweden. 1979.

[4] Lindahl S., "Design and simulation of a coordinated Drum Boiler turbine controller", LUTFD2 (TFRT-3143). ITL. Sweden. 1976

[5] Chopade S. S., Pradhuman Verma, Prashant Verma, "Simulation of Boiler Control using PLC \& SCADA", International Journal of
Engineering and Advanced Technology, Vol. 3, Issue 3, December 2013

[6] Zhuo W., Yanyan J., Shichao W., "The application of feedforward PID control in water level control system, World Automation Congress (WAC)", pp. 1-3 June 2012

[7] Dey N., Mandal R., Subashini M. M., “Design and Implementation of a Water Level Controller using Fuzzy Logic", International Journal of Engineering and Technology, Vol 5, No 3, pp. 2277-2285, Jun-Jul 2013

[8] Shome A., Ashok S. D., "Fuzzy Logic Approach for Boiler Temperature \& Water Level Control", International Journal of Scientific \& Engineering Research, Volume 3, Issue 6, June-2012

[9] Zhang Y., Xu Li-Wei, Chen P., Guan Xiao-Chen , Wang Geng-Jie, "Multivariable Fuzzy Control of CFB Boiler Combustion System", World Congress on Engineering and Computer Science 2013 Vol II WCECS 2013, San Francisco, 23-25 October, 2013

[10] Vakula V.S., Sudha K.R, Naidu I.E.S., 'Structure preserving controller for load frequency control of a fossil fueled steam power plant with nonlinearities", IEEE Workshop on Computational Intelligence: Theories, Applications and Future Directions, IIT Kanpur July 2013

[11] Leanmark M., Kumbirayi M., Tawanda M., "Application of an online Fuzzy Logic remote condition monitoring on water tube Boilers-Babcock and Wilcox (British) and La Mont (French) Boilers (Anonymous Company in Zimbabwe)", International Journal of Application or Innovation in Engineering \& Management, Volume 2, Issue 4, April 2013

[12] Dimeo R., Lee Kwang Yang, "Boiler-turbine control system design usign a Genetic Algorithm", IEEE Transactions on Energy Conversion, Vol. 10, No. 4, December 1995

[13] WU J., Shen J., Krug M., Nguang S.K., Yiguo LI, “GA-based nonlinear predictive switching control for a Boiler-turbine system", Journal of Control Theory Applications, Vol. 10 (1), pp. 100-106, 2012

[14] Hassanein O.I., Aly A. A., Ahmed A. Abo-Ismail, "Parameter Tuning via Genetic Algorithm of Fuzzy Controller for Fire Tube Boiler", International Journal of Intelligent Systems and Applications, Vol. 4, pp. 9-18, 2012

[15] Nasri A., Gasbaoui B., "Novel power flow problem solutions method's based on genetic algorithm optimization for banks capacitor compensation using an Fuzzy Logic rule bases for critical nodal detections", Power engineering and electrical engineering, Vol. 9, Number 4, 2011

[16] Singh P.K., Bhanot S., Mohanta H.K., “Optimized and SelfOrganized Fuzzy Logic Controller for pH Neutralization Process", I.J. Intelligent Systems and Applications, Vol. 12, pp. 99-112, 2013

[17] Pelusi, D., Vazquez, L., Diaz, D., Mascella, R., “Fuzzy algorithm control effectiveness on Drum Boiler simulated dynamics", 36th International Conference on Telecommunications and Signal Processing, TSP 2013, pp. 272-276, 2013

[18] Pelusi, D., Mascella, R. “Optimal control algorithms for second order systems", Journal of Computer Science, 9 (2), pp. 183-197, 2013

[19] Pelusi, D., "Designing neural networks to improve timing performances of intelligent controllers", Journal of Discrete Mathematical Sciences and Cryptography, 16 (2-3), pp. 187-193, 2013

[20] Pelusi, D., Tivegna, M., Ippoliti, P., “'Improving the profitability of Technical Analysis through intelligent algorithms", Journal of Interdisciplinary Mathematics, 16 (2-3), pp. 203-215, 2013

[21] Pelusi, D., "PID and intelligent controllers for optimal timing performances of industrial actuators", International Journal of Simulation: Systems, Science and Technology, 13 (2), pp. 65-71, 2012

[22] Pelusi, D., "Improving settling and rise times of controllers via intelligent algorithms", Proceedings - 2012 14th International Conference on Modelling and Simulation, UKSim 2012, pp. 187-192, 2012 


\section{PELUSI et al: CONTROL OF DRUM BOILER DYNAMICS VIA AN OPTIMIZED FUZZY CONTROLLER}

[23] Pelusi, D., "'Genetic-neuro-Fuzzy controllers for second order control systems", Proceedings - UKSim 5th European Modelling Symposium on Computer Modelling and Simulation, EMS 2011, pp. 12-17, 2011

[24] Pelusi, D., “On designing optimal control systems through genetic and neuro-Fuzzy techniques", IEEE International Symposium on Signal Processing and Information Technology, ISSPIT 2011, pp. 134-139, 2011

[25] Pelusi, D., " Optimization of a Fuzzy Logic controller using genetic algorithms", Proceedings - 3rd International Conference on Intelligent Human-Machine Systems and Cybernetics, IHMSC 2011, 2, pp. 143146,2011

[26] Usoro P.B., "Modelling and simulation of a Drum Boiler-turbine power plant under emergency state control". M.S. thesis, Massachusetts Inst. of Tech. 1977. USA

[27] Eklund K., "'Linear Drum Boiler-turbine models", PhD Thesis. TFRT - 1001. ITL. Sweden. 1971.

[28] Working Group on Prime Mover and Energy Supply Models for System Dynamic Performance Studies, "Dynamic Models for Fossil Fueled Steam Units in Power System Studies", IEEE Transactions on Power Systems, Vol. PWRS-6, May 1991. pp. 753-761.

[29] Balchen J., Larsen G.(1997). "Control of a steam Boiler by elementary nonlinear decoupling (END)", Proceedings of the NATO Advanced Study Institute on Nonlinear Model Based Process Control, Antalya, Turkey, 1997

[30] Aström K.J and Bell, R.D., “Drum - Boiler Dynamics", Automatica, Vol.36, pp. 363-378, 2000.

[31] Wing J. M., "Computational thinking". Communications of the ACM.Vol. 49, No.3. 2006.

[32] Magnus H., "XSteam for Matlab", 2006. \$http://www.xeng.com/XSteam_Matlab.htm\$

[33] Prego J.J.G., Vazquez Seisdedos L., Tailor-made small simulator for a Drum Boiler control based on linear techniques, IEEE Conference on Emerging Technologies \& Factory Automation (ETFA), 978-14577-0017-0, pp. 1-4, 2011

[34] Chopra S., Mitra R., Kumar V., “Fuzzy Controller: Choosing an Appropriate and Smallest Rule Set", International Journal of Computational Cognition, Vol. 3, NO. 4, December 2005

[35] Alcala R., Benitez J. M., Casillas J., Cordon O., Perez R., “Fuzzy Control of HVAC Systems Optimized by Genetic Algorithms", Applied Intelligence Vol. 18, pp. 155-177, 2003

[36] Yang S., Ming Li, Bin Xu, Bin Guo, Chuangao Zhu, “'Optimization of Fuzzy Controller Based on Genetic Algorithm", International Conference on Intelligent System Design and Engineering Application (ISDEA), Vol. 2, pp 21-28, 2010

[37] Holland, J. H., Adaptation in Natural and Artificial Systems, Cambridge, MA: MIT Press., Second Edition (1992)

[38] Ling S.H., Frank H.F. Leung, H.K. Lam, Yim-Shu Lee, Peter K. S Tam, A novel Genetic-Algorithm-based Neural Network for shortterm load forecasting, IEEE Transaction on Industrial Electronics, Vol. 50, NO. 4, August 2003

[39] Leng G., McGinnity T.M., Prasad G., Design for self-organizing Fuzzy neural networks based on Genetic Algorithms, IEEE Transactions on Fuzzy Systems, Vol. 14, NO. 6, December 2006

[40] Akbarzadeh-T M.R., Kumbla K., Tunstel E., Jamshidi M., Soft computing for autonomous robotic systems, Computers and Electrical Engineering, 26, pp. 5-32, 2000

\section{APPENDIX (SWEDEN POWER PLANT [27])}

- Active power: $160 \mathrm{MW}$

- Steam mass flow rate: $138.9 \mathrm{~kg} / \mathrm{s}$

- Drum pressure: $15 \mathrm{MPa}$

- Drum water temperature: 342.1 y

- Feed water temperature: $300 \mathrm{y}$

\section{Drum boiler dynamic [3]}

- $\left[V_{-}\{\mathrm{wt}\}, \mathrm{P}, \mathrm{A} \_\mathrm{r}, \mathrm{V} \_\{\mathrm{sd}\}\right]^{\wedge} \mathrm{T}:$ State variables

- $\left[\mathrm{q}_{-} \mathrm{f}, \mathrm{q} \mathrm{p}\right]^{\wedge} \mathrm{T}:$ Control input variables.

- $\left[\mathrm{T} \_f, q \_s\right]^{\wedge} \mathrm{T}:$ Disturbance input variables

- $[\mathrm{Y}, \mathrm{P}]$ : Output variables.

- [Y_r,P_r]: Set-points variables.

- V_\{wt $\}\left[\mathrm{m}^{\wedge} 3\right]$ : total water volume.

- Y $[\mathrm{m}]$ : drum water level

- P [Bar] : Drum pressure.

- A_r [Non unit] : the steam quality at the riser outlet

- qff $[\mathrm{kg} / \mathrm{s}]$ : feedwater mass flow rate

- q p [kg/s]: Fuel oil mass flow rate.

- q_s $[\mathrm{kg} / \mathrm{s}]$ : Steam mass flow rate

- T f [ C] : feedwater temperature.

- q_ $\{\mathrm{cd}\}[\mathrm{kg} / \mathrm{s}]$ : Condensation mass flow rate.

TABLE IV. DRUM BOILER CONSTRUCTIVE PARAMETERS

\begin{tabular}{|c|c|c|c|c|}
\hline$A_{d c}\left[\mathrm{~m}^{2}\right]$ & $V_{r}\left[\mathrm{~m}^{3}\right]$ & $k$ & $T_{d}[s]$ & $V_{s d 0}\left[\mathrm{~m}^{3}\right]$ \\
\hline 0.38 & 37 & 25 & 12 & 7.53 \\
\hline \hline$V_{t}\left[\mathrm{~m}^{3}\right]$ & $m_{t}[\mathrm{~kg}]$ & $C_{P}[\mathrm{~J} /(\mathrm{kg} \cdot \mathrm{C})]$ & $m_{r}[\mathrm{~kg}]$ & $m_{d}[\mathrm{~kg}]$ \\
\hline 88 & $3 e^{5}$ & 500 & $16 e^{4}$ & 92432.43 \\
\hline \hline$\beta$ & $V_{d c}\left[\mathrm{~m}^{3}\right]$ & $A d\left[\mathrm{~m}^{2}\right]$ & & \\
\hline 0.3 & 11 & 20 & & \\
\hline \multicolumn{4}{|r|}{} \\
\hline
\end{tabular}

Notations of Table IV:

- A_ $\{\mathrm{dc}\}$ : Area of the cross section of downcomer tubes

- V_r: riser volume.

- $\mathrm{k}$ : friction coefficient in downcomer-riser loop

- T_d : residence time of steam in drum.

- V_t : Total volume of the drum, downcomer, and risers.

- $\mathrm{m} t$ : total metal mass

- $\mathrm{CP}$ : specific heat of the metal

- m_r : total riser mass.

- m_d: Drum metal mass.

- Ibeta : Parameter in an empirical equation

- V_\{dc $\}$ : downcomer volume.

- A_d : wet surface, i.e., drum area at normal operating levē.

TABLE V. STEAdY STATES VALUES

\begin{tabular}{|c|}
\hline Steady state for state variables \\
\hline$p_{o}=85 \mathrm{Bar}, V_{w t o}=57.2 \mathrm{~m}^{3}$ \\
\hline$A_{\text {ro }}=0.051, V_{\text {sdo }}=4.9 \mathrm{~m}^{3}$ \\
\hline Operation values for inputs and outputs \\
\hline$q_{p o}=7[\mathrm{~kg} / \mathrm{s}], q_{\text {fo }}=49.796[\mathrm{~kg} / \mathrm{s}], q_{s o}=49.796[\mathrm{~kg} / \mathrm{s}]$ \\
\hline$T_{\text {fo }}=238.1 \mathrm{C}, Y_{o}=1.20529[\mathrm{~m}], p_{o}=85 \mathrm{Bar}$ \\
\hline
\end{tabular}




\section{PELUSI et al: CONTROL OF DRUM BOILER DYNAMICS VIA AN OPTIMIZED FUZZY CONTROLLER}

Actuator dynamic [4]

- See Table VI

TABLE VI. MAIN PARAMETERS IN ACTUATOR DYNAMIC

\begin{tabular}{|c|}
\hline Fuel flux \\
\hline$\left|y_{e}\right| \leq 0.007 \mathrm{~s}^{-1} 0 \leq y_{e} \leq 14 \mathrm{Kg} / \mathrm{s}$ \\
\hline \hline Water flux \\
\hline$y_{e} \mid \leq 0.05 \mathrm{~s}^{-1} 0 \leq y_{e} \leq 140 \mathrm{Kg} / \mathrm{s}$ \\
\hline
\end{tabular}

Sensor transistors dynamic [33]
- G_\{STP $\}$ : Transfer function for pressure sensortransmitter

- G_\{STY $\}$ : Transfer function for level sensor-transmitter 